\title{
Ectopic Parathyroid Adenoma: How Does Imaging Help Decide the Surgical Approach?
}

Navendu Mohan ${ }^{1}$, Abhiskek K Singh², Sudhanshu Tiwari ${ }^{3}$, Azim Anwar $^{4}$, Manish Gutch ${ }^{5}$, Shashwat Verma ${ }^{6}$, Nidhi Anand ${ }^{7}$, Shilpi Misra ${ }^{8}$, Roma Pradhan ${ }^{9}$

\begin{abstract}
Keywords: Computed tomography, Ectopic parathyroid adenoma, Intraoperative parathyroid hormone. World Journal of Endocrine Surgery (2019): 10.5005/jp-journals-10002-1275
\end{abstract}

A 32-year-old lady presented with history of recurrent calculi for last 9 years. The patient also gave history of five abortions in past 4 years; the first miscarriage occurred 4 years back while the recent one was 2 months back. None of these pregnancies could be sustained for more than 2 months. For recurrent renal stones, she was evaluated and was found to have high calcium levels hence was referred to the endocrinologist. On further evaluation intact parathyroid hormone (PTH) was found to be high (218 pg/mL: normal 11-67 pg/mL). Neck examination was unremarkable. With the report of high PTH and high calcium, a diagnosis of primary hyperparathyroidism was made. To localize the adenoma usg and Tc-99m sestamibi (sesta-methoxyisobutylisonitrile) (MIBI) were done; MIBI revealed that the parathyroid was lying in an ectopic location possibly deep in the left suprasternal region. For anatomical localization of the lesion, contrast enhanced computed tomography (CECT) neck and mediastinum was done in order to guide us about the surgical approach. CECT neck showed a small well-defined $(13 \times$ $8 \mathrm{~mm}$ ) heterogeneously enhancing lesion medial to the left common carotid artery near its origin from the arch. On reconstructed images (Fig. 1C), it was found that the adenoma is at the level of the brachiocephalic vein just behind the manubrium sterni and thus it was thought that cervical delivery may be possible; however, close relationship with the brachiocephalic vein was to be kept in mind by the surgeon. Hence, the patient was taken for surgery with a plan for attempting cervical delivery along with intraoperative parathyroid hormone monitoring (IOPTH). Intraoperatively, it was found at the upper end of the left thymic limb at the level of the brachiocephalic vein and was dissected carefully taking part of
1-4,9 Department of Endocrine Surgery, Dr Ram Manohar Lohia Institute of Medical Sciences, Lucknow, Uttar Pradesh, India

${ }^{5}$ Department of Endocrinology, Dr Ram Manohar Lohia Institute of Medical Sciences, Lucknow, Uttar Pradesh, India

${ }^{6}$ Department of Nuclear Medicine, Dr Ram Manohar Lohia Institute of Medical Sciences, Lucknow, Uttar Pradesh, India

${ }^{7}$ Department of Pathology, Dr Ram Manohar Lohia Institute of Medical Sciences, Lucknow, Uttar Pradesh, India

${ }^{8}$ Department of Anaesthesia, Dr Ram Manohar Lohia Institute of Medical Sciences, Lucknow, Uttar Pradesh, India

Corresponding Author: Roma Pradhan, Department of Endocrine Surgery, Dr Ram Manohar Lohia Institute of Medical Sciences, Lucknow, Uttar Pradesh, India, Phone: +91 9732221166, e-mail: drromapradhan@gmail.com

How to cite this article: Mohan N, Singh AK, Tiwari S, et al. Ectopic Parathyroid Adenoma: How Does Imaging Help Decide the Surgical Approach? World J Endoc Surg 2019;11(3):103.

Source of support: Nil

Conflict of interest: None

thymus inferiorly. Every effort was made to avoid capsule rupture in order to avoid parathyromatosis.

Intraoperative PTH testing was done and showed more than $50 \%$ drop at 10 minutes. Frozen section report confirmed parathyroid tissue and thymus.

Postoperatively, she had fall in serum calcium levels and was managed with oral calcium and vitamin D.
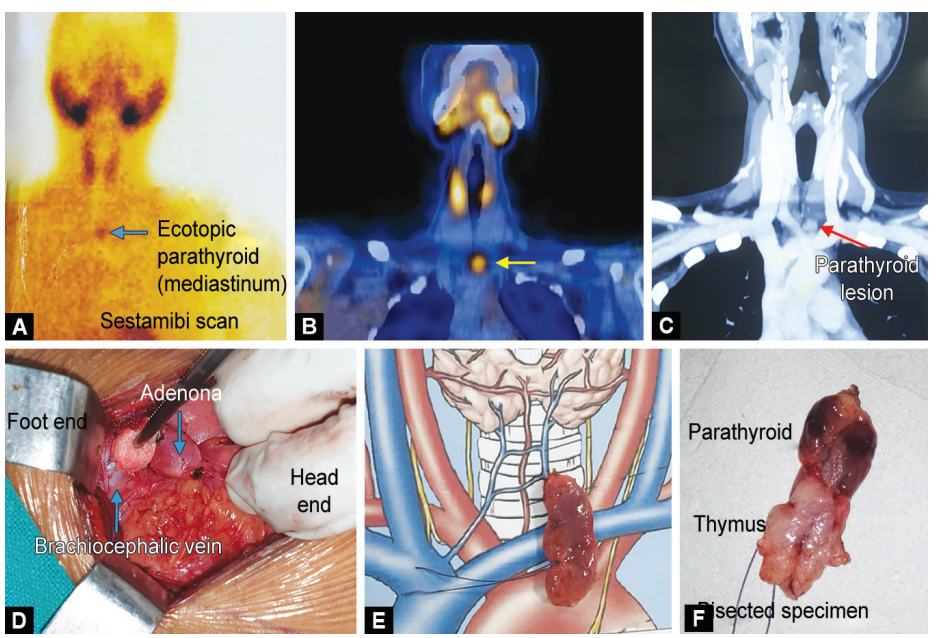

Figs 1 A to F: (A) Sestamibi scan; (B) SPECT CT image; (C) Reconstructed CECT image; (D) Intraoperative image; (E and F) Postoperative specimen

(-) The Author(s). 2019 Open Access This article is distributed under the terms of the Creative Commons Attribution 4.0International License (https://creativecommons. org/licenses/by-nc/4.0/), which permits unrestricted use, distribution, and non-commercial reproduction in any medium, provided you give appropriate credit to the original author(s) and the source, provide a link to the Creative Commons license, and indicate if changes were made. The Creative Commons Public Domain Dedication waiver (http://creativecommons.org/publicdomain/zero/1.0/) applies to the data made available in this article, unless otherwise stated. 